\title{
German budget cuts cast chill wind over outlook for international labs
}

London. The German government is sending shock waves through Europe's scientific community by proposing to reduce its contribution to the support of five international per cent in the next financial year.

The reduced subscriptions, the details of which are yet to be fully agreed, are a result of the harsh cuts in public spending announced two weeks ago by the conservative government of Chancellor Helmut Kohl as a step towards meeting the agreed criteria for membership of the single European currency (see Nature 382, 196; 1996).

While being presented by Germany primarily as a move designed to curb public spending and increase the efficiency with which research funds are spent, many scientists fear that it could help crystallize a general move throughout Europe to reduce spending on international basic science facilities, where these cannot demonstrate a likely contribution to the creation of economic wealth.

The European Laboratory for Particle Physics (CERN), in Geneva, is likely to be one of the hardest hit. Preliminary figures being circulated by the Federal Ministry of Education, Research and Technology in Bonn indicate that the government is from DM265.7 million (US $\$ 178$ million) in 1996 to DM249.80 million next year.

Other bodies facing potential cuts in their German support include the European Molecular Biology Laboratory (EMBL) in Heidelberg, the European Southern Observatory, which is based in Garching and operates telescopes in Chile, and the Institute Laue Langevin (ILL) in Grenoble (see below). In percentage terms, the biggest reduction would be in Germany's contribution to the European Synchrotron Radiation Facility (ESRF), in Grenoble, which would fall by 10.2 per cent in constant terms.

Research ministers attending a private meeting recently of the industrialized nations belonging to the so-called G7 group are said to have discussed the growing problems many of them face in sustaining their subscriptions to international scientific organizations.

"It seems likely that, before long, a thorough analysis will be carried out of all major scientific projects to determine which are really necessary now, and which could be postponed to release funding for social programmes," Boris Saltykov, Russia's minister for science and technology policy, told a press conference in Moscow research organizations by an average of six proposing to reduce spending on CERN shortly after returning from the meeting.

According to Saltykov, international projects are a particular target, as taxpayers do not understand why a substantial amount of their money is being spent abroad at a time when scientists are not receiving enough support at home. Germany, it appears, is no longer immune to this dilemma. Indeed, Jürgen Rüttgers, the country's research minister, is said to have described to his fellow G7 ministers a growing feeling in Bonn of the need to replace the country's previous largesse with a more hard-headed approach.

The implications of the proposed cuts are already sending a chill around the five international organizations concerned. This is particularly true since,

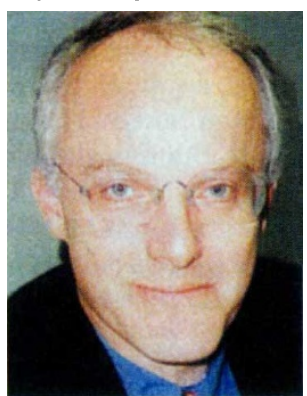
Rüttgers: period of largesse is over. in most cases, Germany's share of their budget is determined by a legally-binding treaty, and could not be reduced without accepting a comparable reduction in the contributions from other member states.

Officials in Bonn say that, in the short term, they expect to find ways to ensure that their commitments are met. In the longterm, they add, their goal is primarily to make German researchers more closely involved in decisions about distributing research funds between competing projects.

But Yves Petroff, for example, the director of ESRF, points out that if Germany's proposed move is copied by other member states, the result could be a major financial blow to the ESRF's research programmes, as much of its budget is already committed to salaries and basic running costs. "That could even mean that we would have to shut down for about six months," he says.

It would also make it impossible to complete the facility's remaining beam-lines. If that were to happen, he says, it would be

Proposed reductions in German contributions to European laboratories (DM million)

\begin{tabular}{lrrr} 
& 1996 actual & 1997 planned & reduction \\
European Laboratory for Particle Physics (CERN) & 265.7 & 249.8 & $-6.0 \%$ \\
European Molecular Biology Laboratory (EMBL) & 22.2 & 21.2 & $-4.5 \%$ \\
European Southern Observatory (ESO) & 38.6 & 37.5 & $-\mathbf{2 . 8} \%$ \\
European Synchrotron Radiation Facility (ESRF) & 30.3 & 27.2 & $-\mathbf{1 0 . 2} \%$ \\
Institut Laue-Langevin (ILL) & 32.9 & 30.8 & $-6.4 \%$ \\
& & & \\
\hline TOTAL & 389.7 & 366.5 & $-6.0 \%$ \\
Source: Bundesministerium für Bildung Wissenschaft, Forscing
\end{tabular}

Source: Bundesministerium für Bildung, Wissenschaft, Forschung und Technologie serious problem, and I am very worried." national scientific facilities are funded. domestic physics programme. Taylor said. with Carl Levitin \& Quirin Schiermeier "extremely detrimental" to the ESRF. "Obviously from my point of view it is a very

There are similar concerns at the potential implications of the proposed reductions among German scientists. "The type of international collaboration represented by CERN is exemplary," says Volker Soergel, a former director of the DESY Research Centre in Hamburg. "I would hope that the people in Bonn would understand that if they are trying to develop new approaches."

But British officials, while expressing their own reservations about the possible impact of substantial cuts if not handled sensitively, are keen to point out that the German move indicates that they are no longer isolated in wanting to re-appraise how inter-

During a parliamentary debate last Friday, for example, Britain's science minister, Ian Taylor, said that now other countries "are becoming concerned about budgets", there was an opportunity to "work closely with the Germans" on the difficulties both countries faced in finding the money to support the construction of the LHC while at the same time maintaining a healthy

"It is absurd for us to have budgets that mean that we are effectively funding others to do research because we do not have enough left in our own budgets to carry out our national programmes, or get involved nationally in some of the work at the LHC,"

Earlier, in a letter to Peter Williams, the chairman of the Particle Physics and Astronomy Research Council, he pointed out that, as a result of recent changes in voting rules, Britain and Germany can jointly block any future spending plans for CERN if they so choose. But science policy officials in other countries, faced with their own funding problems, indicate that Britain and Germany are not alone in seeking alternative, possibly drastic, solutions. David Dickson, (see also pages 288 and 291 ) 